CLINICAL STUDY

\title{
Effects of high-dose octreotide LAR on glucose metabolism in patients with acromegaly inadequately controlled by conventional somatostatin analog therapy
}

Gherardo Mazziotti, Teresa Porcelli, Fausto Bogazzi ${ }^{1}$, Giovanna Bugari ${ }^{2}$, Salvatore Cannavò ${ }^{3}$, Annamaria Colao Renato Cozzi $^{5}$, Laura De Marinis ${ }^{6}$, Ettore degli Uberti ${ }^{7}$, Silvia Grottoli ${ }^{8}$, Francesco Minuto ${ }^{9}$, Marcella Montini ${ }^{10}$, Maurizio Spinello ${ }^{11}$ and Andrea Giustina

Department of Medical and Surgical Sciences, University of Brescia, 25125 Brescia, Italy, ${ }^{1}$ Department of Endocrinology, University of Pisa, 56124 Pisa, Italy, ${ }^{2}$ Department of Biomedical Sciences and Biotechnology, University of Brescia, 25125 Brescia, Italy, ${ }^{3}$ Section of Endocrinology, Department of Medicine and Pharmacology, University of Messina, 98125 Messina, Italy, ${ }^{4}$ Department of Molecular and Clinical Endocrinology and Oncology,

University Federico II, 80125 Naples, Italy, ${ }^{5}$ Division of Endocrinology, Ospedale Niguarda, 20149 Milan, Italy, ${ }^{6}$ Pituitary Unit, Division of Endocrinology, Catholic University of the Sacred Heart, 00168 Rome, Italy, ${ }^{7}$ Section of Endocrinology, Department of Biomedical Sciences and Advanced Therapies, University of Ferrara, 44100 Ferrara, Italy, ${ }^{8}$ Department of Internal Medicine, Endocrinology, and Metabolic Diseases, University of Turin, 10153 Turin, Italy, ${ }^{9}$ Department of Endocrine and Medical Sciences, University of Genova, 16132 Genova, Italy, ${ }^{10}$ Division of Endocrinology, Ospedali Riuniti, 24100 Bergamo, Italy and ${ }^{11}$ Novartis Farma S.p.A, 21040 Origgio, Italy

(Correspondence should be addressed to A Giustina who is now at Endocrine Service, Montichiari Hospital, Via Ciotti 154, 25018 Montichiari, Italy; Email: a.giustina@libero.it)

\begin{abstract}
Objective: In this study, the effect of high-dose octreotide LAR on glucose metabolism in patients with acromegaly was investigated.

Design: A post-hoc analysis of a clinical trial enrolling 26 patients with acromegaly not controlled by standard maximal somatostatin analog (SSAs) dose and randomized to receive high-dose (60 mg/28 days) or high-frequency $(30 \mathrm{mg} / 21$ days) octreotide i.m. injection (octreotide LAR) for 6 months.

Methods: Glucose metabolic status was defined as worsened when a progression from normoglycemia to impaired fasting glucose (IFG) or from IFG to diabetes occurred or when an increase of HbAlc by at least $0.5 \%$ was demonstrated. An improvement of glucose metabolism was defined in the presence of a regression from IFG to normoglycemia and/or when HbAlc decreased by at least $0.5 \%$.

Results: Glucose metabolic status remained unchanged in a majority of patients $(16 / 26$ patients, $65.3 \%$ ), worsened in six patients, and improved in four patients. Pre-existing metabolic status did not predict worsening of glucose metabolism, which, conversely, was significantly related to persistent biochemical activity of the disease. In fact, patients with worsened glucose metabolism exhibited a less frequent decrease in serum GH and IGF1 levels, compared with patients with improved or unchanged glucose metabolism $(2 / 6$ vs $18 / 20 ; P=0.01)$.

Conclusion: An increase in octreotide LAR dose or frequency did not impact on glucose metabolism in most patients. Worsening of glucose metabolic status occurred in close relation with persistently uncontrolled acromegaly.
\end{abstract}

European Journal of Endocrinology 164 341-347

\section{Introduction}

Acromegaly is a rare disease characterized by increased cardiovascular morbidity and mortality (1). Impaired glucose tolerance and diabetes mellitus are frequent complications, occurring in up to $50 \%$ of patients affected by acromegaly, and insulin resistance is an important factor in the development of cardiovascular complications in patients with acromegaly (2-4). The abnormalities of glucose homeostasis are closely associated with growth hormone $(\mathrm{GH})$ hypersecretion, as $\mathrm{GH}$ opposes the effects of insulin on carbohydrate metabolism (2-4).
Long-acting somatostatin analogs (SSAs) are effective in the treatment of acromegaly and may correct GH/insulin-like growth factor 1 (IGF1) hypersecretion and control complications in a subset of patients $(2,3$, 5-7). However, the activity of SSAs on several peripheral tissues can also cause undesired effects. In particular, SSAs may induce abnormalities of glucose metabolism due to inhibition of insulin secretion $(8,9)$. As study results to date have been equivocal, we recently performed a meta-analysis to assess the effects of SSAs on glucose metabolism. This analysis demonstrated that SSAs, when administered at conventional 
dosing regimens, may have only a marginal clinical impact on glucose homeostasis in patients with acromegaly (10). However, it is still unknown whether clinically significant abnormalities of glucose metabolism may result from treatment with high-dose SSAs. A recent randomized study has demonstrated that high doses of octreotide LAR are well tolerated and effective in normalizing IGF1 in a subset of patients with acromegaly that were previously inadequately controlled by conventional SSA therapy (11). In the present study, we performed a post-hoc analysis of the glycometabolic data acquired during this trial. The aim of our work was to evaluate whether high-dose octreotide LAR was able to induce significant abnormalities in glucose metabolism in patients on long-term treatment with conventional doses of SSAs.

\section{Materials and methods}

This post-hoc analysis was performed on 26 patients with persistently uncontrolled acromegaly under maximal conventional SSA doses, who had been enrolled in a prospective multicenter, randomized, controlled, open-label study, the results of which have been published recently (11). The protocol was approved by the ethical committee of the Principal Investigator (A G: ethical committee of Spedali Civili di Brescia on behalf of the National Health Authority) and by all local ethical committees of each participating center. All patients provided written informed consent to participate in the study. The study was preregistered at ClinicalTrials.gov; registration number: NCT00372697. The inclusion and exclusion criteria are detailed in the original publication (11).

Patients were randomized to receive octreotide LAR $30 \mathrm{mg}$ administered every 21 days for 6 months (highfrequency group) or octreotide LAR $60 \mathrm{mg}$ administered every 28 days for 6 months (high-dose group). Octreotide LAR $60 \mathrm{mg}$ was administered as two $30 \mathrm{mg}$ injections. The primary outcome measures were mean change in IGF1 and GH serum concentrations from baseline to month 6 . The secondary outcome measures were the proportion of patients achieving IGF 1 reduction $\geq 20 \%$ (to limit the confounding effect of assay variability), IGF1 normalization (according to pre-specified normal ranges for age), clinically relevant tumor shrinkage (tumor volume decrease of $\geq 20 \%$ versus baseline), and safety and tolerability evaluations. For the purpose of this post-hoc analysis, we analyzed the biochemical parameters of glucose homeostasis, which were collected during the study (i.e. serum glycosylated hemoglobin (HbAlc), fasting plasma glucose (FPG), and fasting plasma insulin (FPI)) measured at enrollment and after 6 months of treatment. Patients were characterized as having diabetes mellitus if FPG levels were $\geq 126 \mathrm{mg} / \mathrm{dl}$ or if they were on active antidiabetic treatments (12). Impaired fasting glucose
(IFG) was defined if FPG fell between 100 and $125 \mathrm{mg} / \mathrm{dl}(12)$. Patients were defined normoglycemic if FPG was $<100 \mathrm{mg} / \mathrm{dl}$ and $\mathrm{HbAlc}$ values were $\leq 6 \%$ (12). Glucose metabolism was defined as worsened during high-dose or high-frequency octreotide LAR therapy when a progression from normoglycemia to IFG or from IFG to diabetes occurred or when an increase of $\mathrm{HbAlc}$ by at least $0.5 \%$ was demonstrated. An improvement in glucose metabolism was defined by the presence of a regression from IFG to normal glucose levels and/or when HbAlc decreased by at least $0.5 \%$.

\section{Statistical analysis}

Data are expressed as median and range. Paired and unpaired data were compared using Wilcoxon's and Mann-Whitney's $U$ tests respectively. Multiple comparisons were made by Friedman's and Kruskal-Wallis' tests, with post-hoc Bonferroni's correction. Fisher's exact test was used for unpaired comparison of proportions. Repeated frequencies were compared via the McNemar's test. Pearson's coefficient was used to assess correlations. To test the independent effects of FPI and GH/IGF1 changes on outcome of glucose metabolism during octreotide LAR treatment, the partial correlation coefficient was calculated. Statistical significance was considered to be $P<0.05$.

\section{Results}

At the study entry (i.e. under conventional maximal SSA dose regimens), 7 patients $(26.9 \%)$ had diabetes mellitus (three treated with metformin, one with insulin, and three on diet alone), 8 patients $(30.8 \%)$ had IFG, whereas 11 patients were normoglycemic (Table 1). No significant differences in the prevalence of diabetes mellitus ( 33.3 vs $18.2 \%, P=0.39$ ) or IFG ( 26.7 vs $36.4 \%$; $P=0.60$ ) were observed in the highfrequency versus high-dose group respectively.

In patients receiving high-dose octreotide, a significantly greater number of patients (10 out of $11,91 \%$ ) achieved a reduction (of any magnitude) in serum IGF1 concentration at 6 months than those in the highfrequency group ( 8 out of $15,53 \% ; P<0.05$ ) (Table 2 ). In the high-dose group, the median serum IGF1 concentration at month 6 was significantly lower $(P=0.02)$ than baseline. The percentage GH and IGF1 changes at the end of the study versus baseline were statistically significant in the high-dose group $(-28$ and $-27 \%$ for $\mathrm{GH}$ and IGF1 respectively; $P<0.05$ for both values), but not in the high-frequency group $(+6$ and $-5 \%$ for GH and IGF 1 respectively; $P>0.05$ for both values).

According to the criteria reported in the Materials and Methods section, glucose metabolism remained unchanged in the majority of patients $(16 / 26$ patients, $65.3 \%$ ), whereas changes in FPG and HbAlc were 
Table 1 Baseline demographical and clinical data of 26 patients with acromegaly randomized to high-dose or high-frequency octreotide LAR.

\begin{tabular}{|c|c|c|c|c|c|c|c|c|c|c|}
\hline \multirow[b]{2}{*}{ Cases } & \multirow[b]{2}{*}{ Sex/age } & \multicolumn{3}{|c|}{ Pre-study therapy } & \multirow[b]{2}{*}{$\begin{array}{c}\text { GH } \\
(\mu \mathrm{g} / \mathrm{l})\end{array}$} & \multirow[b]{2}{*}{$\begin{array}{l}\text { IGF1 } \\
(\mu \mathrm{g} / \mathrm{l})\end{array}$} & \multirow[b]{2}{*}{$\begin{array}{l}\text { FPG } \\
(\mathrm{mg} / \mathrm{dl})\end{array}$} & \multirow[b]{2}{*}{$\begin{array}{c}\text { HbAlc } \\
(\%)\end{array}$} & \multirow[b]{2}{*}{$\begin{array}{l}\text { FPI } \\
(\mathrm{mU} / \mathrm{l})\end{array}$} & \multirow{2}{*}{$\begin{array}{c}\text { Basal } \\
\text { glycometabolic } \\
\text { status }\end{array}$} \\
\hline & & Drug & $\begin{array}{c}\text { Dose } \\
\text { (mg/28 days) }\end{array}$ & $\begin{array}{l}\text { Duration } \\
\text { (months) }\end{array}$ & & & & & & \\
\hline 1 & $\mathrm{M} / 50$ & $\mathrm{OCT}$ & 30 & 7 & 4.6 & 458.0 & 120.0 & 5.5 & 19.8 & IFG \\
\hline 2 & $F / 69$ & OCT & 30 & 7 & 14.2 & 601.0 & 113.0 & 6.7 & 46.5 & IFG \\
\hline 3 & $F / 66$ & OCT & 30 & 7 & 5.3 & 389.0 & 109.0 & 6.4 & 2.0 & Diabetes $^{a}$ \\
\hline 4 & $\mathrm{M} / 56$ & OCT & 30 & 35 & 4.9 & 511.0 & 80.0 & 5.7 & 19.8 & Normal \\
\hline 5 & $\mathrm{M} / 40$ & $\begin{array}{l}\text { OCT } \\
\text { AN FB }\end{array}$ & 30 & 35 & 2.0 & 386.0 & 91.0 & 5.4 & 4.3 & Normal \\
\hline 6 & $\mathrm{M} / 52$ & OCT & 30 & 95 & 9.3 & 556.0 & 91.0 & 5.8 & 8.2 & Normal \\
\hline 7 & $\mathrm{~F} / 37$ & OCT & 30 & 23 & 8.5 & 479.0 & 89.0 & 5.4 & 6.7 & Normal \\
\hline 8 & $\mathrm{M} / 27$ & OCT & 30 & 68 & 10.3 & 551.0 & 88.0 & 5.9 & 6.3 & Normal \\
\hline 9 & $\mathrm{M} / 65$ & OCT & 30 & 91 & 2.5 & 277.0 & 116.0 & 6.2 & 5.3 & IFG \\
\hline 10 & $\mathrm{M} / 45$ & OCT & 30 & 19 & 6.0 & 303.0 & 104.0 & 6.0 & 5.2 & IFG \\
\hline 11 & $F / 36$ & LAN ER & 120 & 6 & 9.7 & 756.0 & 89.0 & 6.2 & 9.0 & Diabetes $^{b}$ \\
\hline 12 & $\mathrm{M} / 49$ & ОСТ & 30 & 80 & 5.1 & 289.0 & 93.0 & 5.9 & 7.9 & Normal \\
\hline 13 & $\mathrm{M} / 43$ & OCT & 30 & 67 & 7.5 & 612.0 & 93.0 & 5.0 & 15.0 & Normal \\
\hline \multirow[t]{2}{*}{14} & $\mathrm{~F} / 32$ & LAN SR & 90 & 4 & 5.9 & 770.0 & 132.0 & 7.0 & 29.0 & Diabetes $^{a}$ \\
\hline & & LAN ER & 120 & 6 & & & & & & \\
\hline 15 & $F / 68$ & OCT & 30 & 100 & 4.0 & 384.0 & 126.0 & 6.4 & 4.2 & Diabetes $^{b}$ \\
\hline 16 & $\mathrm{~F} / 51$ & OCT & 30 & 73 & 3.2 & 265.0 & 115.0 & 5.2 & 7.1 & IFG \\
\hline 17 & $\mathrm{M} / 53$ & OCT & 30 & 17 & 4.2 & 292.0 & 101.0 & 5.2 & 2.5 & IFG \\
\hline 18 & $\mathrm{M} / 78$ & OCT & 30 & 7 & 9.2 & 243.0 & 163.0 & 8.6 & 2.0 & Diabetes $^{c}$ \\
\hline 19 & $\mathrm{~F} / 56$ & OCT & 30 & 6 & 5.5 & 492.0 & 87.0 & 6.1 & 2.9 & Normal \\
\hline 20 & $\mathrm{M} / 54$ & OCT & 30 & 31 & 38.0 & 891.0 & 99.0 & 5.9 & 8.2 & Normal \\
\hline 21 & $\mathrm{~F} / 56$ & OCT & 30 & 47 & 5.5 & 364.0 & 76.0 & 6.0 & 2.9 & Normal \\
\hline \multirow[t]{2}{*}{22} & $\mathrm{~F} / 43$ & LAN SR & 90 & 5 & 2.2 & 417.0 & 72.0 & 5.0 & 22.0 & Normal \\
\hline & & OCT & 30 & 2 & & & & & & \\
\hline 23 & $F / 38$ & OCT & 20 & 32 & 20.0 & 476.0 & 104.0 & 5.6 & 9.7 & IFG \\
\hline 24 & $F / 49$ & OCT & 30 & 41 & 3.2 & 302.0 & 100.0 & 5.9 & 8.7 & IFG \\
\hline 25 & $\mathrm{~F} / 47$ & OCT & 30 & 35 & 3.2 & 412.0 & 104.0 & 7.1 & 4.9 & Diabetes $^{a}$ \\
\hline \multirow[t]{2}{*}{26} & $\mathrm{~F} / 67$ & LAN SR & 90 & 4 & 6.3 & 364.0 & 133.0 & 6.2 & 6.2 & Diabetes $^{\mathrm{b}}$ \\
\hline & & OCT & 30 & 76 & & & & & & \\
\hline
\end{tabular}

M, male; F, female; LAN SR, lanreotide-sustained release; LAN ER, lanreotide-extended release; OCT, octreotide LAR; IGF1, insulin-like growth factor 1; FPG, fasting plasma glucose; FPI, fasting plasma insulin; IFG, impaired fasting glucose.

aDiabetes treated with metformin.

${ }^{b}$ Diabetes treated with diet alone.

${ }^{\mathrm{C}}$ Diabetes treated with insulin.

observed in only ten patients (six worsened and four improved). At the study end, eight patients (30.8\%) had diabetes mellitus ( $P=0.32$ versus baseline), and eight patients $(30.8 \%)$ had IFG (NS versus baseline). No significant $(P=0.62)$ difference in the outcome of glucose metabolism was observed between the highdose (Table 2) and high-frequency (Table 3) groups. Pooling together data from high-dose and highfrequency groups, the rate of worsening in glucose metabolism was comparable between patients with preexisting diabetes mellitus ( 2 out of 7, 28.6\%) and those with IFG ( 2 out of $8,25.0 \%$ ) or normoglycemic ( 2 out of $11,18.2 \%)$, whereas the improvement in glucose metabolism was more frequently $(P=0.02)$ observed in patients with pre-existing diabetes ( 3 out of $7,42.9 \%$ ) as compared to the other two groups of patients ( 0 and $9.1 \%$ for IFG and normoglycemic respectively).

Percent changes in GH and IGF1 values at the end of the study versus baseline were significantly different in the three groups. In fact, in six patients with worsened glucose metabolism, an increase in GH and IGF1 levels was observed, whereas GH and IGF1 decreased in patients whose glucose metabolism improved or did not change (Fig. 1A and B). Analysis of individual outcomes demonstrated that patients with worsened glucose metabolism exhibited a less frequent decrease (of any magnitude) in serum GH and IGF1 levels, compared with the other patients whose glucose metabolism either improved or did not change ( $2 / 6$ vs $18 / 20$; $P=0.01)$.

High-dose and high-frequency octreotide LAR treatment caused an increase in FPI (range from +1.2 to $+158.6 \%$ ) in 14 patients and a decrease in FPI (range from -73.1 to $-20.2 \%$ ) in the remaining 12 patients (Tables 2 and 3). The decrease in FPI occurred more frequently $(P=0.03)$ in patients with worsening in glucose metabolism (5 out $6,83.3 \%$ ) as compared to patients whose glucose metabolism improved or did not change (7 out of $20,35.0 \%$ ).

Reduction in FPI $(r:-0.59 ; P=0.003)$ and increase in GH $(r: 0.44 ; P=0.03)$ and IGF1 values $(r: 0.51$; $P=0.008$ ), but not baseline glucose metabolism 
Table 2 Outcome of acromegaly and glucose metabolism parameters in patients randomized to high-dose octreotide LAR treatment.

\begin{tabular}{|c|c|c|c|c|c|c|c|c|c|c|c|c|}
\hline \multirow[b]{2}{*}{ Cases } & \multicolumn{2}{|c|}{$\mathbf{G H}(\mu \mathrm{g} / \mathrm{l})$} & \multicolumn{2}{|c|}{ IGF1 $(\mu \mathrm{g} / \mathrm{l})$} & \multicolumn{2}{|c|}{ FPG $(\mathrm{mg} / \mathrm{dl})$} & \multicolumn{2}{|c|}{ HbAlc (\%) } & \multicolumn{2}{|c|}{ FPI $(\mathrm{mU} / \mathrm{l})$} & \multirow{2}{*}{$\begin{array}{c}\text { Basal } \\
\text { glycometabolic } \\
\text { status }\end{array}$} & \multirow{2}{*}{$\begin{array}{l}\text { Glycometabolic } \\
\text { outcome }\end{array}$} \\
\hline & T0 & T6 & T0 & T6 & T0 & T6 & T0 & T6 & TO & T6 & & \\
\hline 1 & 4.6 & 3.7 & 458.0 & 607.0 & 120.0 & 126.0 & 5.5 & 5.8 & 19.8 & 13.2 & IFG & Worsened \\
\hline 2 & 14.2 & 19.1 & 601.0 & 559.0 & 113.0 & 171.0 & 6.7 & 7.5 & 46.5 & 15.0 & IFG & Worsened \\
\hline 3 & 5.3 & 6.2 & 389.0 & 284.0 & 109.0 & 89.0 & 6.4 & 6.3 & 2.0 & 2.8 & Diabetes $^{a}$ & Unchanged \\
\hline 4 & 4.9 & 1.1 & 511.0 & 120.0 & 80.0 & 83.0 & 5.7 & 6.1 & 19.8 & 13.2 & Normal & Unchanged \\
\hline 5 & 2.0 & 2.6 & 386.0 & 376.0 & 91.0 & 92.0 & 5.4 & 5.4 & 4.3 & 8.3 & Normal & Unchanged \\
\hline 6 & 9.3 & 1.9 & 556.0 & 122.0 & 91.0 & 86.0 & 5.8 & 5.5 & 8.2 & 8.3 & Normal & Unchanged \\
\hline 7 & 8.5 & 5.5 & 479.0 & 202.0 & 89.0 & 79.0 & 5.4 & 5.5 & 6.7 & 11.0 & Normal & Unchanged \\
\hline 8 & 10.3 & 3.5 & 551.0 & 446.0 & 88.0 & 87.0 & 5.9 & 5.3 & 6.3 & 9.5 & Normal & Improved \\
\hline 9 & 2.5 & 2.0 & 277.0 & 263.0 & 116.0 & 122.0 & 6.2 & 6.4 & 6.2 & 8.5 & IFG & Unchanged \\
\hline 10 & 6.0 & 3.5 & 303.0 & 219.0 & 104.0 & 115.0 & 6.0 & 6.1 & 6.0 & 2.8 & IFG & Unchanged \\
\hline 11 & 9.7 & 5.6 & 756.0 & 648.0 & 89.0 & 87.0 & 6.2 & 5.4 & 9.0 & 4.8 & Diabetes $^{b}$ & Improved \\
\hline
\end{tabular}

IGF1, insulin-like growth factor 1; FPG, fasting plasma glucose; FPI, fasting plasma insulin; T0, baseline; T6, 6-month treatment.

aDiabetes treated with metformin.

${ }^{b}$ Diabetes treated with diet alone.

( $r: 0.1 ; P=0.63)$, baseline GH $(r:-0.06 ; P=0.76)$, and IGF1 $(r: 0.21 ; P=0.30)$ values, were significant predictors of worsened glucose homeostasis. The impact of increased serum IGF1 and/or GH values on worsened glucose metabolism remained significant even after correction for changes in FPI $(r=0.48 ; P=0.01)$. Worsening of glucose metabolism during high-dose and high-frequency octreotide LAR was not significantly correlated with duration of conventional SSAs treatment prior to randomization $(r: 0.1 ; P=0.6)$.

\section{Discussion}

This post-hoc analysis of the results of a recently published randomized clinical trial (11) shows that an increase in octreotide LAR dose or frequency results in worsened glucose metabolism in $\sim 25 \%$ of this population of patients with acromegaly poorly controlled by conventional SSA dose regimens. The observed worsening in glucose metabolism was correlated with decreased FPI at the study end, as well as persistently high serum GH and IGF1 values.

Abnormalities of glucose metabolism frequently occur in patients with acromegaly as a direct result of GH hypersecretion on glucose and lipid metabolism (2). Patients with acromegaly are insulin resistant either at the liver or at the peripheral level, displaying hyperinsulinemia and increased glucose turnover in the basal and post-absorptive states. SSA therapy has been shown to impair glucose metabolism in patients with acromegaly by inhibition of insulin secretion (13-15). However, previous results of studies investigating this issue have been controversial, and a meta-analysis of published data suggests that SSA treatment may have only a marginal impact on glucose metabolism in

Table 3 Outcome of acromegaly and glucose metabolism parameters in patients randomized to high-frequency octreotide LAR treatment.

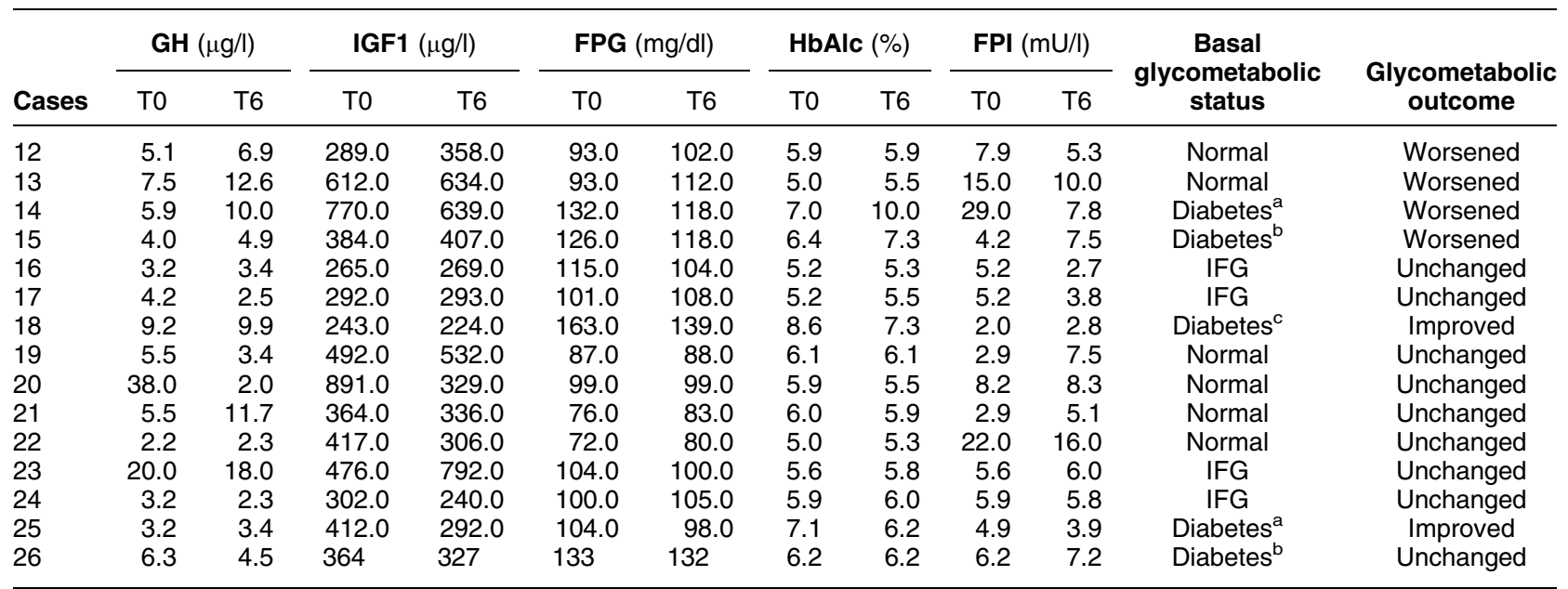

IGF1, insulin-like growth factor 1; FPG, fasting plasma glucose; FPI, fasting plasma insulin; T0, baseline; T6, 6-month treatment

${ }^{a}$ Diabetes treated with metformin.

biabetes treated with diet alone.

${ }^{c}$ Diabetes treated with insulin. 

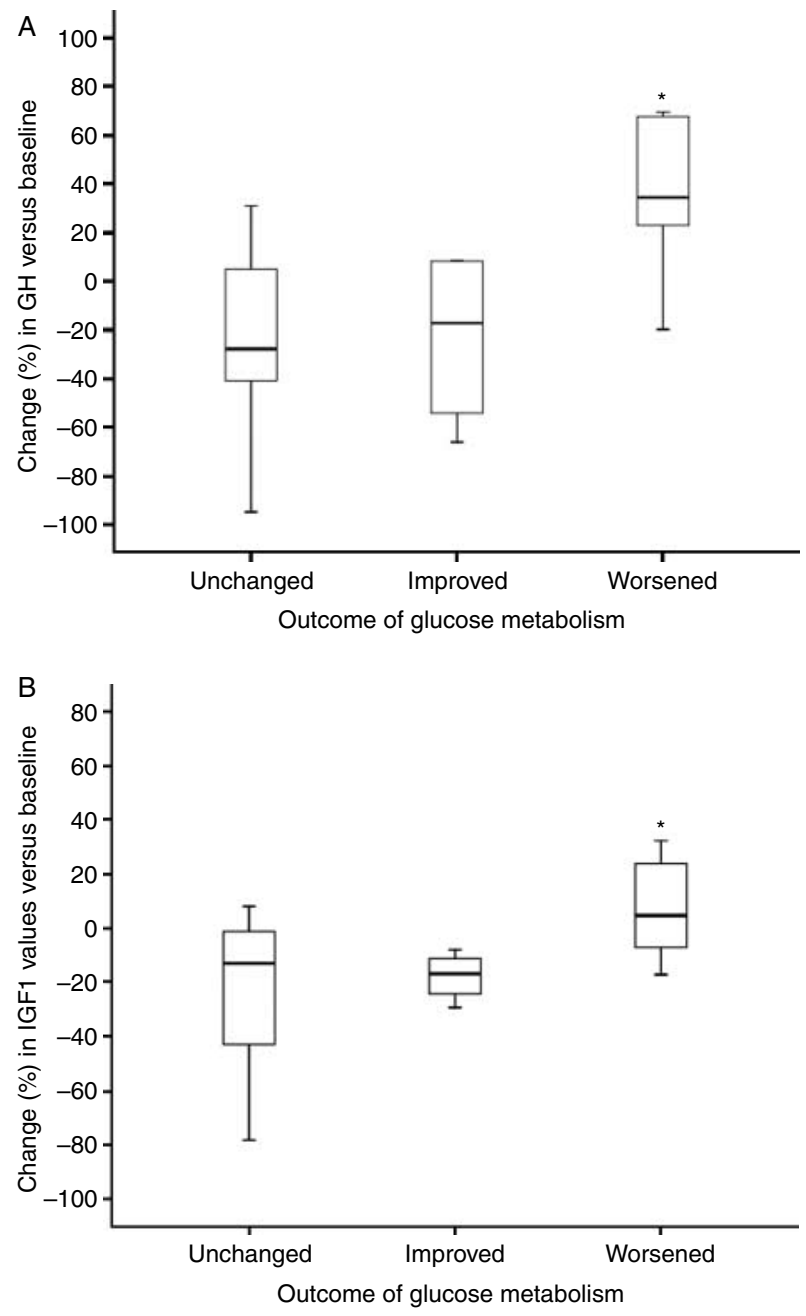

Figure 1 Change (\%) of serum GH (A) and IGF1 (B) values versus baseline during high-dose or high-frequency octreotide LAR treatment in 26 patients with acromegaly stratified according to the outcome of glucose metabolism (6 patients with worsened glucose metabolism; 4 patients with improved glucose metabolism; 16 patients with unchanged glucose metabolism). The plots show the median (thick horizontal line), 25th and 75th percentiles (boxed area), and 3rd and 97 th percentiles (bars). ${ }^{\star} P<0.05$, patients with worsened glucose metabolism versus patients with improved and unchanged glucose metabolism.

patients with acromegaly treated with conventional dosing regimens (10).

In a recent prospective, randomized study, we demonstrated that high-dose octreotide LAR $(60 \mathrm{mg}$ every 4 weeks) may provide beneficial effects in terms of an IGF1 decrease and normalization in patients with acromegaly who were inadequately controlled by conventional SSA dosing regimens, the compliance to which was assessed on the basis of clinical judgment in each participating center (11). At these high doses, octreotide LAR may produce biological effects that are different from those occurring at lower doses. In particular, it was hypothesized that high-dose octreotide
LAR could exert its activity via receptor subtypes other than $\mathrm{sst}_{2}$, such as $\mathrm{sst}_{5}$, for which octreotide has a lower affinity (11). It is noteworthy that the sst $_{5}$ receptor is involved in the regulation of insulin production by pancreatic $\beta$-cells, with potential negative effects mediated by SSA-dependent receptor activation (16). Indeed, it is still unclear whether inhibition of insulin secretion may result in impaired glucose metabolism in patients with insulin resistance, as is frequently the case in patients with acromegaly $(10,16-19)$.

An interesting finding of this analysis was the association between worsening in glucose metabolism and persistence of elevated serum GH and IGF1 values during high-dose and high-frequency octreotide LAR treatment. This association appeared to be independent of baseline metabolic condition and variation in insulin secretion during treatment. This finding is consistent with the hypothesis that $\mathrm{GH}$ hypersecretion is the main determinant of abnormal glucose metabolism in both untreated and treated acromegaly (3). Moreover, highdose and high-frequency octreotide LAR showed comparable risk in terms of glucose metabolism impairment. It is noteworthy that patients treated with high-dose octreotide LAR received higher cumulative doses than patients treated with the high-frequency regimen and demonstrated better biochemical control (11). These findings confirm that impairment of glucose metabolism may not be correlated with the dose of SSAs, but may be dependent on the biochemical control of acromegaly.

Our study has some limitations. First of all, our study was not aimed to assess the overall effects of SSAs on glucose metabolism in acromegaly. No data were collected in this trial on the glucose metabolism status prior to the beginning of conventional SSA treatment. Therefore, no comparisons can be made between the glycometabolic effects of conventional versus high-dose SSA treatment. Moreover, the length of treatment with conventional doses was generally much longer than the duration of the high-dose trial making difficult any comparisons between the two schedules. Furthermore, glycometabolic status of our patients at the study entry was that expected based on epidemiological data $(2,3)$ as well as on meta-analytic evaluations suggesting a minor clinical impact of conventional somatostatin schedule on glucose metabolism (10). It cannot be excluded that any side effect of SSA on glucose metabolism had been established in sensitive patients during the first period of SSA treatment, such that an increase in dose as employed in the present paper would be less likely to promote additional deterioration $(20,21)$. In fact, this trial included only patients partially sensitive to SSAs. In terms of evolution of glucose metabolism, this may be a selection bias since patients resistant to SSAs, possibly with significantly altered glucose metabolism, may have been switched to other treatment modalities before enrollment (22). However, since these patients were all not controlled by SSAs, 
it could be argued that this population represents a clinically relevant model to study the potential negative glycometabolic effects of high-dose SSAs, which is consistent with the hypothesis that these patients could be assumed to be at high risk of developing abnormalities in glucose homeostasis (10). Glucose homeostasis was investigated by assaying FPG and $\mathrm{HbAlc}$, but information on the potential effects of highdose and high-frequency octreotide LAR on plasma glucose during an oral glucose tolerance test was not available as this is not routinely assessed in the followup of acromegaly during SSA treatment (23). There is evidence that an impaired oral glucose tolerance test may occur more frequently than impaired FPG during SSA treatment (10). This limitation is partially compensated by the fact that in our study, we reported the outcome of HbAlc, which is an integrated measure of glucose homeostasis (12). Furthermore, criteria characterizing the worsening in glucose metabolism were arbitrarily defined, but were sufficiently strict to include subjects with changes of minor clinical significance in FPG and HbAlc. In fact, only two of the 26 patients enrolled in the trial had an increase in HbAlc $\geq 1 \%$ at 6 months. Finally, changes in glycometabolic control patients with acromegaly and diabetes may be influenced by other variables independent of GH/IGF1 levels, such as adherence to treatment, increase in body weight, and changes in diet.

Besides these limitations, our analysis may have interesting clinical implications. In particular, these data strengthen the concept that high-dose octreotide LAR is substantially well tolerated in acromegaly and may be a feasible therapeutic option even in the presence of pre-existing alterations of glucose metabolism. Further studies are needed to clarify the cost effectiveness of highdose octreotide LAR as compared to pegvisomant, a GH receptor antagonist, which appears to have no negative effects on glucose homeostasis and can be used to treat patients with acromegaly who are not controlled with conventional SSA regimens (24-28). Our study also shows that, even if rare, a clinically significant worsening in glucose metabolism may occur with high-dose or high-frequency octreotide therapy, highlighting the need to monitor glycometabolic homeostasis during intensive regimens of octreotide LAR.

In conclusion, the increase in octreotide LAR dose or frequency did not have a detrimental effect on glucose metabolism in the majority of patients included in the trial. In the minority of patients who experienced impaired glucose homeostasis, this event occurred more frequently in those with persistently uncontrolled acromegaly, and it could not be predicted based on preexisting abnormalities in glucose metabolism.

\section{Declaration of interest}

Prof. A Giustina is a consultant for Ipsen, Italfarmaco, and Novartis, and has received lecture fees from Pfizer, Ipsen, and Italfarmaco.
Prof. A Colao has received research grant support from IPSEN, Italfarmaco, Novartis, and Pfizer; has received speaker fees from IPSEN, Italfarmaco, and Novartis; and has served on advisory boards for IPSEN and Novartis. M Spinello is employee of Novartis Farma, Italy. The remaining authors have no conflicts of interest.

\section{Funding}

Financial support for the study was provided by Novartis Farma S.p.A, Origgio, Italy. The funding source was used to design and conduct the study, data analysis and editorial support. ClinicalTrials.gov; registration number: NCT00372697.

\section{Acknowledgements}

We wish to thank Dr Vincenza Vinaccia (Novartis Farma S.p.A.) for help in the study design and for conducting statistical analyses. Data collection and management were carried out by OPIS s.r.l., Desio, Italy, and Technical editing and English language assistance were provided by Mary Hines, Wolters Kluwer Health, on behalf of Novartis Farma S.p.A., Origgio, Italy.

\section{References}

1 Melmed S. Medical progress: acromegaly. New England Journal of Medicine 2006355 2558-2573. (doi:10.1056/NEJMra062453)

2 Colao A, Ferone D, Marzullo P \& Lombardi G. Systemic complications of acromegaly: epidemiology, pathogenesis, and management. Endocrine Reviews 200425 102-152. (doi:10. 1210/er.2002-0022)

3 Giustina A, Casanueva FF, Cavagnini F, Chanson P, Clemmons D, Frohman LA, Gaillard R, Ho K, Jaquet P, Kleinberg DL, Lamberts SW, Lombardi G, Sheppard M, Strasburger CJ, Vance ML, Wass JA \& Melmed S. Diagnosis and treatment of acromegaly complications. Journal of Endocrinological Investigation 200326 1242-1247.

4 Jaffrain-Rea ML, Moroni C, Baldelli R, Battista C, Maffei P, Terzolo M, Correra M, Ghiggi MR, Ferretti E, Angeli A, Sicolo N, Trischitta V, Liuzzi A, Cassone R \& Tamburrano G. Relationship between blood pressure and glucose tolerance in acromegaly. Clinical Endocrinology 200154 189-195. (doi:10.1046/j.13652265.2001.01206.x)

5 Freda PU, Katznelson L, van der Lely AJ, Reyes CM, Zhao S \& Rabinowitz D. Long-acting somatostatin analog therapy of acromegaly: a meta-analysis. Journal of Clinical Endocrinology and Metabolism 200590 4465-4473. (doi:10.1210/jc.2005-0260)

6 Melmed S, Casanueva F, Cavagnini F, Chanson P, Frohman LA, Gaillard R, Ghigo E, Ho K, Jaquet P, Kleinberg D, Lamberts S, Laws E, Lombardi G, Sheppard MC, Thorner M, Vance ML, Wass JA \& Giustina A. Consensus statement: medical management of acromegaly. European Journal of Endocrinology 2005153 737-740. (doi:10.1530/eje.1.02036)

7 Maison P, Tropeano AI, Macquin-Mavier I, Giustina A \& Chanson P. Impact of somatostatin analogs on the heart in acromegaly. A meta-analysis. Journal of Clinical Endocrinology and Metabolism 200792 1743-1747. (doi:10.1210/jc.2006-2547)

8 Pereira AM, Biermasz NR, Roelfsema F \& Romijn JA. Pharmacologic therapies for acromegaly: a review of their effects on glucose metabolism and insulin resistance. Treatments in Endocrinology 20054 43-53. (doi:10.2165/00024677-20050401000005)

9 Giustina A, Girelli A, Buffoli MG, Cimino A, Legati F, Valentini U \& Giustina G. Low-dose octreotide is able to cause a maximal inhibition of the glycemic responses to a mixed meal in obese type 2 diabetic patients treated with insulin. Diabetes Research and Clinical Practice 1991114 47-54. (doi:10.1016/01688227(91)90052-F) 
10 Mazziotti G, Floriani I, Bonadonna S, Torri V, Chanson P \& Giustina A. Effects of somatostatin analogs on glucose homeostasis: a meta analysis of acromegaly studies. Journal of Clinical Endocrinology and Metabolism 200994 1500-1508. (doi:10. 1210/jc.2008-2332)

11 Giustina A, Bonadonna S, Bugari G, Colao A, Cozzi R, Cannavo S, De Marinis L, Degli Uberti E, Bogazzi F, Mazziotti G, Minuto F, Montini M \& Ghigo E. High-dose intramuscular octreotide in patients with acromegaly inadequately controlled on conventional somatostatin analogue therapy: a randomised controlled trial. European Journal of Endocrinology 2009161 331-338. (doi:10. 1530/EJE-09-0372)

12 American Diabetes Association. Standards of medical care in diabetes - 2010. Diabetes Care 201033 S11-S61. (doi:10.2337/ dc10-S011)

13 Strowski MZ, Parmar RM, Blake AD \& Schaeffer JM. Somatostatin inhibits insulin and glucagon secretion via two receptors subtypes: an in vitro study of pancreatic islets from somatostatin receptor 2 knockout mice. Endocrinology 2000141 111-117. (doi:10.1210/ en.141.1.111)

14 Steffin B, Gutt B, Bidlingmaier M, Dieterle C, Oltmann F \& Schopohl J. Effects of the long-acting somatostatin analogue Lanreotide Autogel on glucose tolerance and insulin resistance in acromegaly. European Journal of Endocrinology 2006155 73-78. (doi:10.1530/eje.1.02185)

15 Boehm BO \& Lustig RH. Use of somatostatin receptor ligands in obesity and diabetic complications. Best Practice and Research. Clinical Gastroenterology 200216 493-509. (doi:10.1053/bega. 2002.0320)

16 Mitra SW, Mezey E, Hunyady B, Chamberlain L, Hayes E, Foor F, Wang Y, Schonbrunn A \& Schaeffer JM. Colocalization of somatostatin receptor $\mathrm{sst}_{5}$ and insulin in rat pancreatic betacells. Endocrinology $19991403790-3796$. (doi:10.1210/en.140. 8.3790)

17 Baldelli R, Battista C, Leonetti F, Ghiggi MR, Ribaudo MC, Paoloni A, D'Amico E, Ferretti E, Baratta R, Liuzzi A, Trischitta V \& Tamburrano G. Glucose homeostasis in acromegaly: effects of long-acting somatostatin analogues treatment. Clinica Endocrinology 200359 492-499. (doi:10.1046/j.1365-2265. 2003.01876.x)

18 Kasayama S, Otsuki M, Takagi M, Saito H, Sumitani S, Kouhara H, Koga M, Saitoh Y, Ohnishi T \& Arita N. Impaired beta-cell function in the presence of reduced insulin sensitivity determines glucose tolerance status in acromegalic patients. Clinical Endocrinology 200052 549-555. (doi:10.1046/j.1365-2265.2000.00986.x)

19 Rizza RA, Mandarino LJ, Genest J, Baker BA \& Gerich JE. Production of insulin resistance by hyperinsulinaemia in man. Diabetologia $1985 \mathbf{2 8}$ 70-75.

20 Giusti M, Ciccarelli E, Dallabonzana D, Delitala G, Faglia G, Liuzzi A, Gussoni G \& Giordano DG. Clinical results of long-term slow-release lanreotide treatment of acromegaly. European Journal of Clinical Investigation 199727 277-284. (doi:10.1046/ j.1365-2362.1997.1190659.x)
21 Lamberts SW, Uitterlinden P, Verschoor L, van Dongen KJ \& del Pozo E. Long-term treatment of acromegaly with the somatostatin analogue SMS 201-995. New England Journal of Medicine 1985 313 1576-1580. (doi:10.1056/NEJM198512193132504)

22 Gola M, Bonadonna S, Mazziotti G, Amato G \& Giustina A. Resistance to somatostatin analogs in acromegaly: an evolving concept? Journal of Endocrinological Investigation 200629 86-89.

23 Giustina A, Chanson P, Bronstein MD, Klibanski A, Lamberts S, Casanueva FF, Trainer P, Ghigo E, Ho K \& Melmed S. A consensus on criteria for cure of acromegaly. Journal of Clinical Endocrinology and Metabolism 201095 3141-3148. (doi:10.1210/jc.20092670)

24 Trainer PJ, Drake WM, Katznelson L, Freda PU, Herman-Bonert V, van der Lely AJ, Dimaraki EV, Stewart PM, Friend KE, Vance ML, Besser GM, Scarlett JA, Thorner MO, Parkinson C, Klibanski A, Powell JS, Barkan AL, Sheppard MC, Malsonado M, Rose DR, Clemmons DR, Johannsson G, Bengtsson BA, Stavrou S, Kleinberg DL, Cook DM, Phillips LS, Bidlingmaier M, Strasburger CJ, Hackett S, Zib K, Bennett WF \& Davis RJ. Treatment of acromegaly with the growth hormone-receptor antagonist pegvisomant. New England Journal of Medicine $2000 \mathbf{3 4 2}$ 1171-1177. (doi:10.1056/ NEJM200004203421604)

25 van der Lely AJ, Hutson RK, Trainer PJ, Besser GM, Barkan AL, Katznelson L, Klibanski A, Herman-Bonert V, Melmed S, Vance ML, Freda PU, Stewart PM, Friend KE, Clemmons DR, Johannsson G, Stavrou S, Cook DM, Phillips LS, Strasburger CJ, Hackett S, Zib KA, Davis RJ, Scarlett JA \& Thorner MO. Long-term treatment of acromegaly with pegvisomant, a growth hormone receptor antagonist. Lancet 2001358 1754-1759. (doi:10.1016/ S0140-6736(01)06844-1)

26 Melmed S, Colao A, Barkan A, Molitch M, Grossman AB, Kleinberg D, Clemmons D, Chanson P, Laws E, Schlechte J, Vance ML, Ho K \& Giustina A. Guidelines for acromegaly management: an update. Journal of Clinical Endocrinology and Metabolism 2009 94 1509-1517. (doi:10.1210/jc.2008-2421)

27 De Marinis L, Bianchi A, Fusco A, Cimino V, Mormando M, Tilaro L, Mazziotti G, Pontecorvi A \& Giustina A. Long-term effects of the combination of pegvisomant with somatostatin analogs (SSA) on glucose homeostasis in non-diabetic patients with active acromegaly partially resistant to SSA. Pituitary $2007 \mathbf{1 0}$ 227-232. (doi:10.1007/s11102-007-0037-7)

28 Colao A, Arnaldi G, Beck-Peccoz P, Cannavò S, Cozzi R, degli Uberti E, De Marinis L, De Menis E, Ferone D, Gasco V, Giustina A, Grottoli S, Lombardi G, Maffei P, Martino E, Minuto F, Pivonello R \& Ghigo E. Pegvisomant in acromegaly: why, when, how. Journal of Endocrinological Investigation 200730 693-699.

Received 23 December 2010

Accepted 6 January 2011 